\title{
Reduction of Temperature in Concentrator Photovoltaic Module Using Coating with High Thermal Emissivity and Conductivity
}

\author{
Satoshi Nakamura ${ }^{1}$, Kazumasa Sakamoto ${ }^{1, a}$ and Kensuke Nishioka ${ }^{1}$ \\ ${ }^{1}$ Faculty of EngineeringUniversity of Miyazaki, 1-1, GakuenKibanadai-nishi, Miyazaki-shi, 889-2192, Japan
}

\begin{abstract}
The temperature of solar cells considerably increases under light-concentrating operations, and the conversion efficiency of solar cells decreases with increasing temperature.It is very important to reduce the cell temperature in concentrator photovoltaic modules. The thermal radiation layers with high thermal emissivity and thermal conductivity was coated on the aluminum samples which is used for the chassis of concentrator photovoltaic and the effect was evaluated under the conditions with wind. The temperature of sample with coating showed lower temperature than that without coating. In the condition with wind, the coated sample with high thermal emissivity and high thermal conductivity showed the lowest temperature due to the effect of thermal radiation and thermal conduction.
\end{abstract}

\section{Introduction}

In recently year, multi-junction solar cells have attracted increasing attention for application in concentrator photovoltaic (CPV) system owing to their very high conversion efficiency [1-3]. Multi-junction solar cells consisting of InGaP, InGaAs, and Ge diodes are recognized as super high efficiency cells and are used for space application. Light concentration is one of the most important factors for the development of an advanced PV system using high-efficiency solar cells. High-efficiency multi-junction cells under high light concentration have been investigated for terrestrial application [4-7].The temperature of solar cells considerably increases under light-concentrating operations, and the conversion efficiency of solar cells decreases with increasing temperature [8-10]. It is therefore very important to reduce the cell temperature in CPV modules. In this study, thermal radiation layers with high thermal emissivity and thermal conductivity was coated on the aluminum samples which is used for the chassis of CPV and the effect was evaluated under the conditions with wind.

\section{Experimental}

Fig. 1 shows the samples used in this study. Aluminum samples(60 mm width $x 95 \mathrm{~mm}$ lengthx $3 \mathrm{~mm}$ thickness) wereprepared. In order to insert a thermalsensor, a hole of $1.1 \mathrm{~mm}$ in diameter with $10 \mathrm{~mm}$ in depth was made at thecenter of cross-section. In order to detect the sample temperature, Pt100 was inserted in the hole. The heat conductive grease was used in the hole to detect the exact temperature. Three aluminum plates were prepared; "high

\footnotetext{
$\overline{\text { aha11012@student.miyazaki-u.ac.jp }}$
}

emissivity type" with high thermal emissivity material, "high emissivity and conductivity type" with high thermal emissivity and high thermal conductivity material and "reference" without coating. The thermal radiation layer [Pelcool (R), PELNOX Ltd.] was coated on the aluminumwhich is used as the material of the chassis of CPV module by a spray coating method. The thickness of the layer was $30 \mu \mathrm{m}$. The layer consisted of acrylate resin and inorganic fillers. Heater was fixed with double faced tape on each sample.

Fig. 2 shows a schematic diagram of sample setup. Three samples were connected with parallel circuit and bias was applied using a biporal power supply with constant voltage operation. The bias voltage was set at 80 $\mathrm{V}$ and the current value was $0.97 \mathrm{~A}$. The temperature was measured every second and accumulated by a data logger.

Fig. 3 shows a schematic diagram of wind tunnel used in this study. Total of 99 pieces AC fans were installed in the wind tunnel, 11 fans in depth and, 9 fans in widths, and they make air flow. Each fan is set directto the servomotor. It is dependently suppressed from spinning by the signalgenerated from a computer every 0.02 seconds. Theturbulence strength is under $2.0 \%$. It proves the high performance of thewind tunnel [11].The size of the wind tunnel was $1,800 \mathrm{~mm}$ in height and 2,540 $\mathrm{mm}$ in width and the distance from blast fan to the samples was $5.6 \mathrm{~m}$. Wind speed was measured with pitot tube that was set at the $1.23 \mathrm{~m}$ front positon of the samples. 

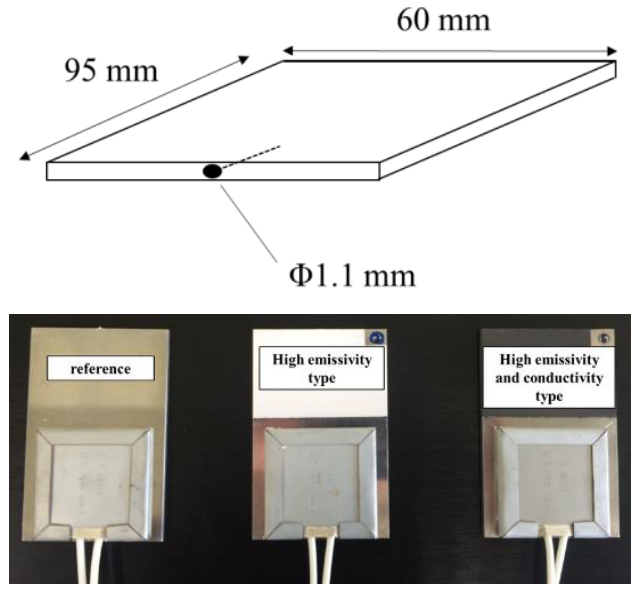

Figure 1.Samples used in this study.

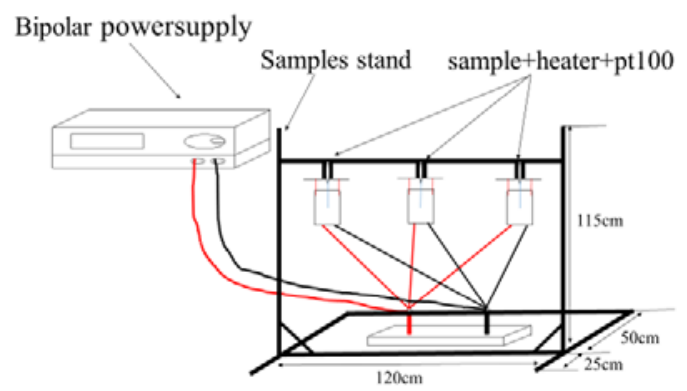

Figure 2.Schematic diagram of sample setup.

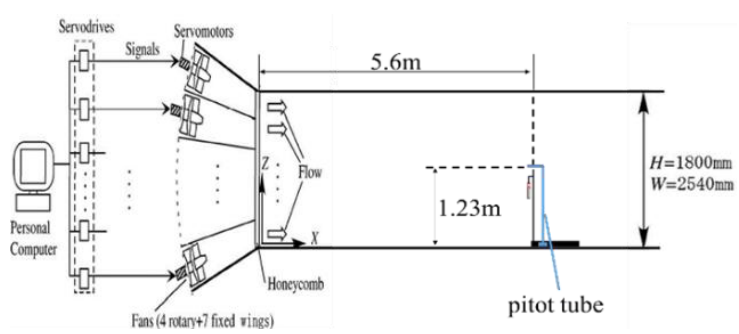

Figure 3.Schematic diagram of wind tunnel.

\section{Results and Discussion}

Fig. 4 shows the temperature of samples for each wind speed. The temperature with coating showed lower temperature than that without coating. The thermal radiation coatings worked well as heat reduction coating.

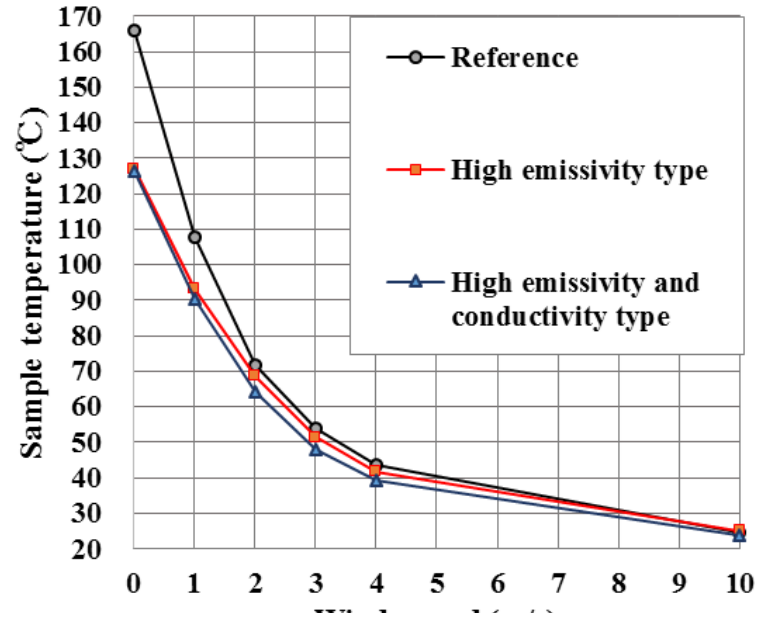

Figure 4.Temperature of samplesfor each wind speed.

When we define a layer of sample's surface [area: $A_{1}\left(\mathrm{~m}^{2}\right)$, emissivity: $\varepsilon_{1}$ ] and an environment [area: infinite], the heat radiation from the sample to the environment $\mathrm{Q}_{12}(\mathrm{~W})$ is given by

$Q_{12}=A_{1} \varepsilon_{1} \sigma\left(T_{1}^{4}-T_{2}^{4}\right)$

where $\sigma, \mathrm{T}_{1}$, and $\mathrm{T}_{2}$ are the Stefan-Boltzmann constant $\left(5.67 \times 10^{-8} \mathrm{~W} / \mathrm{m}^{2} \cdot \mathrm{K}^{4}\right)$, the absolute temperature (K) of the sample, and the absolute temperature $(\mathrm{K})$ of the environment, respectively. It was found that the heat radiation increased with increasing emissivity, and the high emissivity of the thermal radiation layer enhanced the heat radiation from the sample to the environment.For all samples, the temperature decreased with increasing wind speed. It is found that wind is important to decrease the sample temperature.

Fig.5 shows the difference in temperature between "high emissivity and conductivity type" and "high emissivity type" for each wind speed ("difference in temperature" = "temperature of high emissivity and conductivity type"-"high emissivity type"). In the nonwind condition, there is no significantdifference between them. However, with the wind conditions, the difference in temperature became larger with increasing wind speed. When we define a layer of sample's surface [area: $A_{1}\left(\mathrm{~m}^{2}\right)$,thickness: $L_{1}(\mathrm{~m})$, conductivity: $\left.\lambda_{1}\right]$, the thermal conduction of inside the layer $\dot{\mathrm{Q}}_{12}(\mathrm{~W})$ is given by

$\dot{Q}_{12}=A_{1} \lambda_{1} \frac{T_{1}-T_{2}}{L_{1}}$

An increase in thermal conductivity accelerates the heat transfer from the alminum to enironment.Therefore, the temperautre of the sample with high emissivity and conductivity type was lower than that with high emissivity type. However, in the wind condition over 3 $\mathrm{m} / \mathrm{s}$, the difference in temperature became smaller. It is considered that the heat reduction effect of wind is preferable in the wind condition of over $3 \mathrm{~m} / \mathrm{s}$. 


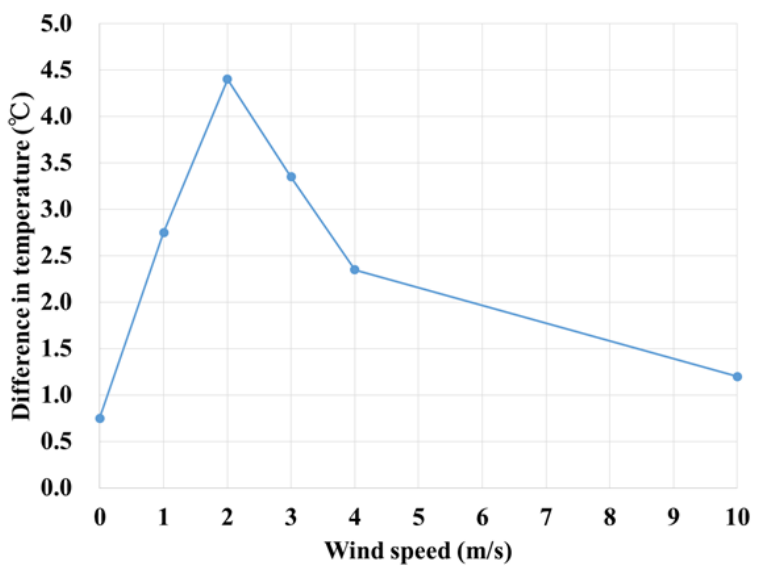

Figure 5.Difference in temperature between high emissivity and conductivity type and high emissivity type for each wind speed (difference in temperature = temperature of high emissivity and conductivity type high emissivity type).

\section{Summary}

The thermal radiation layers with high thermal emissivity and thermal conductivity was coated on the aluminum samples which is used for the chassis of CPV and the effect was evaluated under the conditions with wind. The temperature with coating showed lower temperature than that without coating. For all samples, the temperature decreased with increasing wind speed. It is found that wind is important to decrease the sample temperature. The temperautre of the sample with high emissivity and conductivity type was lower than that with high emissivity type.

\section{References}

1. M. Yamaguchi,Sol. Energy Mater. Sol. Cells. 75,261(2003)

2. M. Yamaguchi, T. Takamoto, K. Araki,Sol. Energy Mater. Sol. Cells.90,57(2006)

3. T. Takamoto, M. Kaneiwa, M. Imaizumi, M. Yamaguchi,Prog. Photovoltaics Res. Appl. 13,495(2005)

4. K. Araki, M. Kondo, H. Uozumi, N.J. Ekins-Daukes, T. Egami, M. Hiramatsu, Y. Miyazaki, M.Yamaguchi,Sol. Energy Mater. Sol. Cells.90,3320(2006)

5. J. Jaus, A.W. Bett, H. Reinecke, E.R. Weber,Prog. Photovoltaics Res.Appl. 19,580(2011)

6. K. Nishioka, T. Takamoto, T. Agui, M. Kaneiwa, Y. Uraoka, T. Fuyuki,Sol. Energy Mater. Sol. Cells.90,57(2006)

7. K. Araki, T. Yano, Y. Kuroda,Optics Express.18 A53(2010)

8. K. Nishioka, T. Hatayama, Y. Uraoka, T. Fuyuki, R. Hagihara, M. Watanabe,Sol. Energy Mater. Sol. Cells.665,75 (2003)
9. K. Nishioka , N. Sakitani, K. Kurobe, Y. Yamamoto, Y. Ishikawa, Y. Uraoka, T. Fuyuki,Jpn. J.Appl. Phys. 42,7175(2003)

10. K. Nishioka, T. Takamoto, T. Agui, M. Kaneiwa, Y. Uraoka, T. Fuyuki,Sol. Energy Mater. Sol. Cells.85 429 (2005)

11. S. Ozono, A. Nishi, H. Miyagi,, J. of Wind Engineering \& Industrial Aerodynamics.94 225(2006) 